\title{
Burden of Childhood Infectious Diseases in the Arab World
}

\author{
Mohamed Lemine Cheikh Brahim AHMED and Jorg Heukelbach
}

\section{Contents}

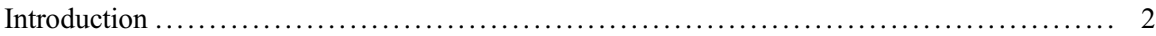

Childhood Infectious Diseases in Arab Countries ................................ 2

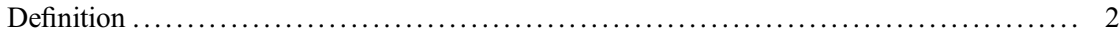

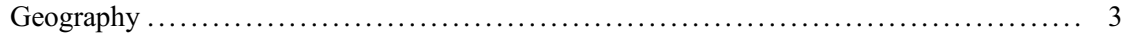

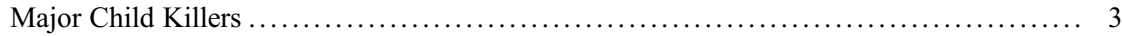

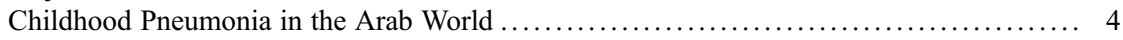

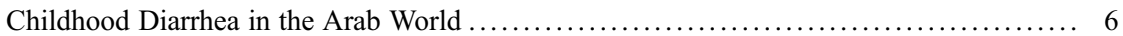

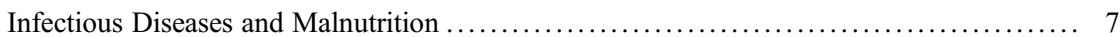

Infectious Diseases and Health Systems in the Arab World $\ldots \ldots \ldots \ldots \ldots \ldots \ldots \ldots \ldots \ldots \ldots$

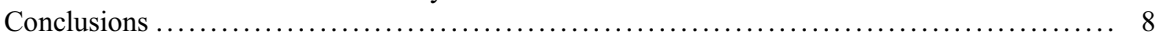

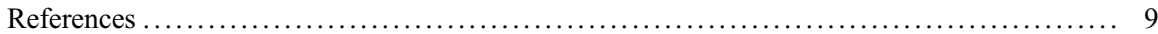

\begin{abstract}
Infectious diseases are leading causes of morbidity and mortality among children under 5 years of age in the developing world, with varying degrees of burden throughout the regions. The Arab world consists of 22 countries with different levels of health financing and availability of human resources. This chapter reviews the burden of infectious diseases in the Arab world, with a focus on pneumonia and diarrheal diseases in children under 5 years of age, and is based on data published during the last 27 years.
\end{abstract}

M. L. C. B. AHMED (ه)

The Mauritanian Association for Scientific Research Development (AMDRS) and Unity of Molecular Epidemiology and Diversity of Microorganisms, Department of Biology, Faculty of Sciences and Techniques, University of Nouakchott El-Asriya, Nouakchott, Mauritania e-mail: lemine1987@hotmail.fr

J. Heukelbach

Department of Community Health, School of Medicine,

Federal University of Ceará, Fortaleza, CE, Brazil 


\section{Keywords \\ Infectious diseases $\cdot$ Childhood $\cdot$ Arab world}

\section{Introduction}

Infectious diseases are the leading cause of global morbidity and mortality. This group of diseases causes approximately 15 million deaths worldwide every year (Abat et al. 2016). A large proportion of the infectious diseases are preventable and/or treatable with sample interventions, but due to weak health system infrastructures in many developing countries, the delivery of interventions to affected populations has been proven to be very difficult (Bhutta et al. 2014). In 1990, the global death toll from infectious diseases in children aged 0-59 months was 6.5 million, while in 2016, the number of deaths in children aged 0-59 months was reduced to about two million (Naghavi et al, 2017). Pneumonia, diarrhea, and malaria were classified as the top three causes of death in humans, especially in low- and middle-income countries (Bagherian et al. 2017). They account for more than $50 \%$ of all postneonatal deaths in the Arab region (Akseer et al. 2015).

Given the high morbidity and mortality caused by these diseases, the World Health Organization (WHO) recommended introducing available vaccines to reduce the disease burden. Consequently, some countries have reduced child mortality by more than half, with reductions in deaths due to pneumonia and diarrhea contributing to $40 \%$ of the overall reduction (Bhutta et al. 2013). Despite such decreases, these diseases are still the major causes of postnatal child deaths, health service attendance, and hospital admissions (Bhutta et al. 2014).

Infectious diseases in children have significant impact not only on the children but also on the families and society, and intensified and integrated efforts are needed to reduce the disease burden. This chapter describes the burden of infectious diseases in the Arab world, with focus on pneumonia and diarrheal diseases among children under 5 years of age, from 1990 to 2017.

\section{Childhood Infectious Diseases in Arab Countries}

\section{Definition}

Infectious diseases are caused by pathogenic microorganisms such as bacteria, fungi, parasites, and viruses that can be transmitted from person to person or from animals to humans, by insects or by ingesting contaminated food and water (Hofman 2016). 


\section{Geography}

The Arab world has a unique geography, with more than 400 million inhabitants. There are 22 Arab diverse states with 3 categories according to their gross national income, namely, low-income countries (LICs; Comoros, Djibouti, Mauritania, Yemen, and Somalia), middle-income countries (MICs; Algeria, Egypt, Iraq, Jordan, Morocco, Libya, Palestine, Soudan, Syria, and Tunisia), and high-income countries (HICs; Bahrain, Kuwait, Oman, Qatar, Saudi Arabia, United Arab Emirates) (Mokdad et al. 2014).

Political instability, inadequate health services, and outbreaks of infectious diseases are common in many Arab countries (Sweileh et al. 2015). Different types of infectious disease, such as polio, pneumonia, and diarrhea, have become a health problem for governments in the Arabic region. There were many outbreaks of infectious diseases in the past years, such as outbreaks of polio in Syria (Arie 2013) and of cholera in Iraq and Soudan (Kur et al. 2009; Khwaif et al. 2010). Several outbreaks attributed to Middle East Respiratory Syndrome (MERS), caused by a corona virus, have mainly been reported from Saudi Arabia (Memish et al. 2014; Al-Ahdal et al. 2012).

The high-income Arab countries, as compared to middle- and low-income Arab countries, have given high priority to the development of health-care services at all levels. As a consequence, the quality of services has greatly improved in recent decades in HICs (Albejaidi 2010). According to the WHO, the health-care system in the region such as Saudi Arabia (ranked 26th) and United Arab Emirates (ranked 27th) comes before many other international health-care systems such as Canada (ranked 30th) and Australia (ranked 32nd) (WHO 2000). However, a number of issues still pose challenges, such as changing patterns of diseases, availability of highly skilled human resources, and practical policies development (Almalki et al. 2011).

\section{Major Child Killers}

Three infectious diseases were ranked as the top causes of deaths worldwide in 2016: lower respiratory infections (three million deaths), diarrheal diseases (1.4 million deaths), and tuberculosis (1.3 million, Liu et al. 2016). They also constitute a major health and socioeconomic challenge in many Arab countries, especially, among children aged 0-5 years. Between 1990 and 2017, pneumonia and diarrheal diseases were always in the top 10 of causes of death in the Arab region (GBD 2017). 
Global

\begin{tabular}{|l|}
\hline 1990 rank \\
\hline 1 Maternal \& neonatal \\
\hline 2 Respiratory infections \& TB \\
\hline 3 Enteric infections \\
\hline 4 Other infectious \\
\hline 5 Other non-communicable \\
\hline 6 NTDs \& malaria \\
\hline 8 Unintentional inj \\
\hline 9 HIV/AIDS \& STIs \\
\hline 10 Transport injuries \\
\hline
\end{tabular}

North Africa and Middle East Both sexes, <5 years, Deaths per 100,000 2017 rank

1990 rank

\begin{tabular}{|l|}
\hline 1 Maternal \& neonatal \\
\hline 2 Respiratory infections \& TB \\
\hline Other non-communicable \\
\hline Enteric infections \\
\hline 6 Unintentional inj \\
\hline Transport injuries \\
\hline 17 Cardiovascular diseases \\
\hline 6 Self-harm \& violence
\end{tabular}

Source: GBD compare: https://vizhub.healthdata.org/gbd-compare/.

\section{Childhood Pneumonia in the Arab World}

Pneumonia kills more children than any other infectious disease, accounting for almost $1 / 5$ of deaths among children worldwide (Wardlaw et al. 2006). In the Arab region, the mortality rates in hospitalized children vary between $10 \%$ and $25 \%$ (AlMuhairi et al. 2016), while the etiological agents and their incidences vary between these countries.

\section{Childhood Pneumonia in High-Income Arab Countries}

Several studies from Arab HICs indicate that childhood pneumonia continues being an important health problem also in these subgroup countries. A cross-sectional study was carried out in the King Khalid University Hospital in Riyadh, Saudi Arabia, on a total of 1429 Saudi children under 5 years of age admitted to the hospital between 1993 and 1996 with complaints suggestive of acute respiratory infections. There were $58 \%$ of cases with bronchiolitis, and $26 \%$ had bronchopneumonia. There was a significant association between bronchiolitis and lower age group 0-6 months, and respiratory syncytial virus was the major causative agent 
of bronchiolitis (Bakir et al. 1998). Another more recent study including 2266 children under 5 years of age with respiratory infections admitted to the King Abdulaziz Medical City in Riyadh, Saudi Arabia, between 2014 and 2015 showed that the most frequent respiratory infections were recorded among children aged 1-5 years with $44.7 \%$, with rhinovirus, adenovirus, and respiratory syncytial virus (RSV) as the most common pathogens (Eifan et al. 2017). A study conducted in Najran between 2012 and 2013 showed also that the frequency of single viral pathogens detected was $56 \%$, viral coinfection was $7 \%$, and mixed viral and bacterial pathogen was $11 \%$ (Al-Ayed et al. 2014). A study conducted on 390 children in Kuwait found $50 \%$ of children with bronchiolitis, $37 \%$ with pneumonia, and $13 \%$ with croup; RSV was the most common viral agent (Hijazi et al. 1997). A retrospective study conducted in Qatar described that $85 \%$ of children had at least one virus, and RSV was the most common agent (Janahi et al. 2017).

\section{Childhood Pneumonia in Middle-Income Arab Countries}

Similar to Arab HICs, childhood pneumonia is an important cause of morbidity and mortality in Arab MICs. For example, a study conducted on 401 children in Algeria showed that $49 \%$ of children with viral infection and syncytial respiratory virus were very frequent among children aged 6-12 months, while the parainfluenza virus type 3 was diagnosed mostly during the second year of life (Kadi et al. 1990). A study conducted in Cairo, Egypt, found that $60 \%$ of children under 5 years of age had a viral infection and more than $10 \%$ a coinfection with two or more viruses. In fact, RSV is the most common viral etiology especially among children aged 0-6 months (Shafik et al. 2012).

Among 372 Tunisian children hospitalized in the Farhat Hached University Hospital, Sousse, Tunisia, between 2013 and 2014, viral pathogens were detected in $92 \%$, with rhinovirus and RSV being the most frequently detected viruses (Brini et al. 2017). Among 700 children hospitalized in the Children Hospital, Rabat, Morocco, respiratory viral viruses were detected in $92 \%$; rhinovirus, RSV, and adenovirus were the most commonly detected viruses (Jroundi et al. 2014).

\section{Childhood Pneumonia in Low-Income Arab Countries}

There are very limited data on childhood pneumonia in Arab LICs. In a survey conducted on 604 Yemeni children less than 2 years of age with acute respiratory infections, RSV was the most common agent (40\%) (Al-Sonboli et al. 2005). Another study from Yemen showed that respiratory viruses, particularly RSV, were commonly associated with hospitalization for acute respiratory infection among children (Hofman 2016). In Mauritania, respiratory disease was associated with $18 \%$ of all hospitalizations and $16 \%$ of all deaths among children hospitalized in a referral hospital in Nouakchott (Ahmed et al. 2018). 


\section{Childhood Diarrhea in the Arab World}

In 2015, diarrhea infections caused nearly 526,000 deaths among children under 5 years of age (Liu et al. 2016). Viral pathogens, especially rotavirus, are the leading cause of diarrhea associated hospitalizations among children under 5 of age throughout the world (Tate et al. 2016). In the Arabic region, diarrheaassociated deaths ranged from 1 per 100,000 children under 5 years of age in high-income Arab countries such as Bahrain and Oman to 471 per 100,000 in low-income Arab countries such as Somalia and Yemen (Khalil et al. 2016).

\section{Childhood Diarrhea in High-Income Arab Countries}

A study conducted in Jeddah (Saudi Arabia) between 1995 and 1996 found that rotavirus was detected in $35 \%$ of the hospitalized children and $6 \%$ of the pediatric outpatients. Escherichia coli was identified in $13 \%$ and Giardia in 3\% of cases (ElSheikh and El-Assouli 2001). In 2000, 25\% of children had diarrheal disease in Jeddah, Saudi Arabia (Al Braiken et al. 2003). A population-based prevalence study conducted in randomly selected children suffering from acute diarrhea in Makkah, Saudi Arabia, in 2008, found that 33\% had viral infection (rotavirus was the major agent with $22 \%$ followed by adenovirus with $7 \%$ ), $5 \%$ were of bacterial origins (Salmonella species were the major cause), and 1\% was found as a parasitic cause (Giardia lamblia) (Johargy et al. 2010). A descriptive study conducted in Najran, Saudi Arabia, showed that $22 \%$ of children had viral pathogens, and rotavirus was the major cause with $17 \% ; 11 \%$ of children were positive for bacterial pathogens, and $1 \%$ had parasitical pathogens (AlAyed et al. 2013). A study conducted in a tertiary care hospital in Riyadh, Saudi Arabia, showed that $32 \%$ had rotavirus and the majority of rotavirus cases were among children under 2 years of age (Aly et al. 2015).

Results from surveillance of rotavirus in Oman showed that rotavirus was detected in $49 \%$ of children hospitalized for acute gastroenteritis. The majority of these cases occurred among children aged 7-17 months (Al Awaidy et al. 2009). Another study from Oman showed that a bacterial etiology was detected in $15 \%$ of children admitted for diarrhea to Ibri regional referral hospital in Dhahira, Oman, with Shigella sp. as the major agent pathogen (Patel et al. 2008).

A study conducted in Al Ain, United Arab Emirates, detected rotavirus in 21\% of cases in all age group, with a predominance in 7-12-month-olds (Ijaz et al. 1994). Similar results were found in another study conducted in a tertiary hospital in the United Arab Emirates, in 2006 (Kurdi et al. 2007). In general, annual mortality rate due to rotavirus was less than 10 per 100,000 children in these countries (Howidi et al. 2012).

\section{Childhood Diarrhea in Middle-Income Arab Countries}

According to a cross-sectional study conducted in Fayoum, Egypt, 46\% of children presenting with diarrhea had detectable enteric pathogens. Bacterial pathogens were detected in $25 \%$, rotavirus in $21 \%$, and cryptosporidium in $15 \%$ of cases (ElMohamady et al. 2006). 
In Irbid, Jordan, enteropathogens were detected in $66 \%$ of cases of acute diarrhea among children under 5 years of age. A single enteric pathogen was detected in $51 \%$, rotavirus, and several types of diarrheagenic E. coli were the most frequently detected among children (Youssef et al. 2000). The etiology of diarrheal diseases in Libya was found in a study conducted in Zliten; rotavirus was detected in 27\%, Salmonella in 13.6\%, and cryptosporidium in 13\% (Ali et al. 2005). In Soudan, viral pathogens were detected in 14\%; rotavirus was the major agent followed by adenovirus (Elhag et al. 2013). In Gaza, Palestine, rotavirus was detected in 28\% of cases, Entamoeba sp. in 15\%, and Shigella sp. in 6\% (AbuElamreen et al. 2008). In Morocco, the overall rates of rotavirus and norovirus infections were $26.6 \%$ and $16 \%$, respectively. Mixed viral infections were detected in 3\% (El Qazoui et al. 2014).

\section{Childhood Diarrhea in Low-Income Arab Countries}

Diarrheal diseases are the leading causes of morbidity and mortality among children in Arab LICs countries. Outbreaks occur periodically and may have devastating consequences. However, systematic data are scarce. According to UNICEF, an outbreak of diarrhea and cholera declared in Yemen in 2016 has been the worst outbreak worldwide, with more than 550,000 suspected cases and 2000 associated deaths; more than half of the suspected cases were among children aged $0-5$ years. According to a recent study conducted on the etiology of diarrhea in Yemen, rotavirus was associated with $45 \%$ of diarrhea cases, and the most prevalent genotypes were G2P[4] (Al-Badani et al. 2014). In Mauritania, diarrhea was associated with $22 \%$ of all hospitalizations and $14 \%$ of all deaths among children hospitalized in a referral hospital in Nouakchott (Ahmed et al. 2018).

\section{Infectious Diseases and Malnutrition}

Over the past 27 years, the Arab world has made great progress in reducing the number of deaths from infectious diseases. Despite the progress, substantial burden of infectious diseases and nutritional causes persist in the Arab LICs.

The risk of death by infectious diseases among children aged 0-5 years is extremely increased in the case of malnutrition. Malnutrition is particularly fatal in combination with pneumonia, diarrhea, malaria, and measles. In addition, infection and micronutrient deficiencies can induce immunodeficiency in healthy children, increasing susceptibility to diarrhea and other infectious diseases. This can lead to a vicious cycle of repeated infections, reduced immunity, and deteriorating nutritional status. A malnourished child has more severe disease episodes and more complications. Diarrheal diseases associated with malnutrition are probably the commonest cause of death in young children and may also increase the risk of pneumonia by causing micronutrient loss, stress on the immune system, and dehydration. 


\section{Infectious Diseases and Health Systems in the Arab World}

Health systems in most Arab countries are still oriented toward curative and episodebased care, and most investments are made in tertiary care-oriented services, rather than public health services focusing on prevention. Reorientation of this strategy is needed toward outreach, management and prevention of diseases, health education, management of comorbidity, and patient self-management. Many of the Arab countries, particularly low- and middle-income countries, need to increase universal health coverage to guarantee access to health care and improve health outcomes. In these countries, demographic and social factors have a major effect on health outcomes. Major issues in the region include mother education and prevention of early marriage and teenage pregnancies. Integrated and interdisciplinary efforts should be made to increase health education and decrease health disparities, involving community and religious leaders in health prevention and promotion.

\section{Conclusions}

Infectious diseases, such as pneumonia and diarrhea, are still the leading causes of morbidity and mortality among children in the Arab world. They account for more than $50 \%$ of all deaths among children in the region. The highest burdens of these infectious diseases are reported from LICs and MICs. Effective interventions could prevent about $2 / 3$ of deaths. The lack of success in delivering these interventions is responsible for the high morbidity and mortality of these diseases in both low- and middle-income Arab countries. The high-income Arab countries have invested heavily in their health systems to improve the quality of health-care services and to reduce the burden of infectious diseases. Despite these efforts, they still face many challenges, including family education, human resource development, and the increased demands for health-care services. These challenges apply as well for the Arab LICs and MICs.

Especially LICs often only have a fragmented health system, with limited access of the population to health care, insufficient primary health-care services, and low awareness of the population in relation to the urgency of health conditions. For example, in Nouakchott, Mauritania, less than $44 \%$ of diseased children were presented to a health-care facility, while only $26 \%$ of households had access to safe drinking water and $70 \%$ to improved latrines (Ahmed et al. 2018).

Despite these difficulties, many countries have implemented effectively vaccine programs aiming at the reduction of fatal cases of diarrheal and respiratory diseases. Due to the high relevance of viral pathogens for pneumonia and diarrhea in the Arab region, there is in fact a need to roll out free rotavirus and PCV13 vaccine through government immunization programmers, to assure the access for children who are in the most urgent need. An integrated action involving health prevention and treatment is needed to reduce the multiple causes of infectious diseases in children, as well as the establishment of systematic surveillance systems 
to monitor trends of infectious diseases burden, detect outbreaks at an early state, and evaluate the effectiveness of interventions.

Malnutrition and undernutrition are key shared risk factors for childhood morbidity and mortality associated with pneumonia and diarrheal diseases, especially in LICs and MICs. Interventions to improve childhood nutrition should be prioritized in these countries, such as Yemen, Mauritania, Soudan, Somalia, and Syria, and included systematically in health and vaccine programs.

\section{References}

Abat C, Chaudet H, Rolain J-M, Colson P, Raoult D (2016) Traditional and syndromic surveillance of infectious diseases and pathogens. Int J Infect Dis 48:22-28

Abu-Elamreen FH, Abed AA, Sharif FA (2008) Viral, bacterial and parasitic etiology of pediatric diarrhea in Gaza, Palestine. Med Princ Pract 17:296-301

Ahmed M, Weddih A, Benhafid M, Bollahi M, Sidatt M, Makhalla K, Mokdad A, Heukelbach J, Filali-Maltouf A (2018) Hospitalizations and deaths associated with diarrhea and respiratory diseases among children aged $0-5$ years in a referral Hospital of Mauritania. Trop Med Infect Dis 3:103

Akseer N, Kamali M, Husain S, Mirza M, Bakhache N, Bhutta ZA (2015) Strategies to avert preventable mortality among mothers and children in the eastern Mediterranean region: new initiatives, new hope. East Mediterr Health J 21:361

Al Awaidy SA, Bawikar S, Al Busaidy S, Baqiani S, Al Abedani I, Varghese R, Abdoan HS, Al Abdoon H, Bhatnagar S, Al Hasini KS (2009) Considerations for introduction of a rotavirus vaccine in Oman: rotavirus disease and economic burden. J Infect Dis 200:S248-S253

Al Braiken FA, Amin A, Beeching NJ, Hommel M, Hart CA (2003) Detection of Cryptosporidium amongst diarrhoeic and asymptomatic children in Jeddah, Saudi Arabia. Ann Trop Med Parasitol 97:505-510

AlAyed MSZ, Asaad AM, Mahdi AA, Qureshi MA (2013) Aetiology of acute gastroenteritis in children in Najran region, Saudi Arabia. J Health Specialties 1:84

Al-Ahdal MN, Al-Qahtani AA, Rubino S, (2012) Coronavirus respiratory illness in Saudi Arabia. J Infect Dev Ctries 6(10):692-694

Al-Ayed MS, Asaad AM, Qureshi MA, Ameen MS (2014) Viral etiology of respiratory infections in children in southwestern Saudi Arabia using multiplex reverse-transcriptase polymerase chain reaction. Saudi Med J 35:1348

Al-Badani A, Al-Areqi L, Majily A, AL-Sallami S, AL-Madhagi A, Amood, AK (2014) Rotavirus diarrhea among children in Taiz, Yemen: Prevalence - risk factors and detection of genotypes. Int J Pediatr 2014

Albejaidi FM (2010) Healthcare system in Saudi Arabia: an analysis of structure, total quality management and future challenges. J Altern Pers Soc Sci 2(2):794-818

Ali MB, Ghenghesh KS, Aissa RB, Abuhelfaia A, Dufani M (2005) Etiology of childhood diarrhea in Zliten, Libya. Saudi Med J 26:1759-1765

Almalki M, FitzGerald G, Clark M (2011) Health care system in Saudi Arabia: an overview

Al-Muhairi S, Zoubeidi T, Ellis M, Nicholls MG, Safa W, Joseph J (2016) Demographics and microbiological profile of Pneumonia in United Arab Emirates. Monaldi Arch Chest Dis 65. https://doi.org/10.4081/monaldi.2006.580

Al-Sonboli N, Hart CA, Al-Aeryani A, Banajeh SM, Al-Aghbari N, Dove W, Cuevas LE (2005) Respiratory syncytial virus and human metapneumovirus in children with acute respiratory infections in Yemen. Pediatr Infect Dis J 24:734-736

Aly M, Al Khairy A, Al Johani S, Balkhy H (2015) Unusual rotavirus genotypes among children with acute diarrhea in Saudi Arabia. BMC Infect Dis 15:192 
Arie S (2013) Polio outbreak leads to calls for a "vaccination ceasefire" in Syria f6682

Bagherian H, Farahbaksh M, Rabiei R, Moghaddasi H, Asadi F (2017) National communicable disease surveillance system: a review on information and organizational structures in developed countries. Acta Inform Med 25:271. https://doi.org/10.5455/aim.2017.25.271-276

Bakir TMF, Halawani M, Ramia S (1998) Viral aetiology and epidemiology of acute respiratory infections in hospitalized Saudi children. J Trop Pediatr 44:100-103

Bhutta ZA, Das JK, Walker N, Rizvi A, Campbell H, Rudan I, Black RE (2013) Interventions to address deaths from childhood pneumonia and diarrhoea equitably: what works and at what cost? Lancet 381:1417-1429

Bhutta ZA, Sommerfeld J, Lassi ZS, Salam RA, Das JK (2014) Global burden, distribution, and interventions for infectious diseases of poverty. Infect Dis Poverty 3:21

Brini I, Guerrero A, Hannachi N, Bouguila J, Orth-Höller D, Bouhlel A, Boughamoura L, Hetzer B, Borena W, Schiela B (2017) Epidemiology and clinical profile of pathogens responsible for the hospitalization of children in Sousse area, Tunisia. PLoS One 12:e0188325

Naghavi M, Abajobir AA, Abbafati C, Abbas KM, Abd-Allah F, Abera SF, Aboyans V, Adetokunboh O, Afshin A, Agrawal A, Ahmadi A (2017) Global, regional, and national agesex specific mortality for 264 causes of death, 1980-2016: a systematic analysis for the Global Burden of Disease Study 2016. The Lancet 390(10100):1151-1210

Eifan SA, Hanif A, AlJohani SM, Atif M (2017) Respiratory tract viral infections and coinfections identified by Anyplex ${ }^{\mathrm{TM}}$ II RV16 detection kit in pediatric patients at a Riyadh tertiary care hospital. Biomed Res Int 2017:1928795

El Qazoui M, Oumzil H, Baassi L, El Omari N, Sadki K, Amzazi S, Benhafid M, El Aouad R (2014) Rotavirus and norovirus infections among acute gastroenteritis children in Morocco. BMC Infect Dis 14:300

Elhag WI, Saeed HA, El Fadhil EO, Ali AS (2013) Prevalence of rotavirus and adenovirus associated with diarrhea among displaced communities in Khartoum, Sudan. BMC Infect Dis 13:209

El-Mohamady H, Abdel-Messih IA, Youssef FG, Said M, Farag H, Shaheen HI, Rockabrand DM, Luby SB, Hajjeh R, Sanders JW (2006) Enteric pathogens associated with diarrhea in children in Fayoum, Egypt. Diagn Microbiol Infect Dis 56:1-5

El-Sheikh SM, El-Assouli SM (2001) Prevalence of viral, bacterial and parasitic enteropathogens among young children with acute diarrhoea in Jeddah, Saudi Arabia. J Health Popul Nutr 19:25-30

Global, GBD, 2017. regional, and national age-sex specific mortality for 264 causes of death, 1980-2016: a systematic analysis for the global burden of disease study 2016. Lancet, 390(10100):1151-210.

Hijazi Z, Pacsa A, El-Gharbawy F, Chugh TD, Essa S, Shazli AE, El-Salam RA (1997) Acute lower respiratory tract infections in children in Kuwait. Ann Trop Paediatr 17:127-134

Hofman P (2016) Infectious disease and parasites. Springer, Cham

Howidi M, Al Kaabi N, El Khoury AC, Brandtmüller A, Nagy L, Richer E, Haddadin W, Miqdady MS (2012) Burden of acute gastroenteritis among children younger than 5 years of age-a survey among parents in the United Arab Emirates. BMC Pediatr 12:74

Ijaz MK, Alharbi S, Uduman SA, Cheema Y, Sheek-Hussen MM, Alkhair ARA, Shalabi AG, Ijaz SS, Bin-Othman SA, Sattar SA (1994) Seasonality and prevalence of rotavirus in Al-Ain, United Arab Emirates. Clin Diagn Virol 2:323-329

Janahi I, Abdulkayoum A, Almeshwesh F, Alkuwari M, Alameri M (2017) Viral aetiology of bronchiolitis in hospitalised children in Qatar. BMC Infect Dis 17:139

Johargy A, Ghazi H, Mumenah A (2010) Frequency of viral, bacterial and parasitic enteropathogens among young children with acute diarrhoea in Saudi Arabia. J Pak Med Assoc 60:456-459

Jroundi I, Mahraoui C, Benmessaoud R, Moraleda C, Tligui H, Seffar M, Kettani SC, Benjelloun BS, Chaacho S, Maaroufi A (2014) The epidemiology and aetiology of infections in children admitted with clinical severe pneumonia to a university hospital in Rabat, Morocco. J Trop Pediatr 60:270-278 
Kadi Z, Bouguermouh A, Belhocine Z, Hamlaoui M, Kermani S, Bakouri S, Chaulet P, Hadji N (1990) Acute respiratory infections of viral origin in the children of Algiers, Algeria based on a seroepidemiological study. Rev Roum Virol (Bucharest, Romania: 1990) 41:197-207

Khalil I, Colombara DV, Forouzanfar MH, Troeger C, Daoud F, Moradi-Lakeh M, El Bcheraoui C, Rao PC, Afshin A, Charara R (2016) Burden of diarrhea in the eastern Mediterranean region, 1990-2013: findings from the global burden of disease study 2013. Am J Trop Med Hyg 95:1319-1329

Khwaif JM, Hayyawi AH, Yousif TI (2010) Cholera outbreak in Baghdad in 2007: an epidemiological study/Flambee du cholera a Bagdad en 2007: etude epidemiologique. East Mediterr Health J 16:584

Kur L, Mounir C, Lagu J, Muita M, Rumunu J, Ochieng B, Weathers A, Nsubuga P, Maes E, Rolle I (2009) Cholera outbreak-southern Sudan, 2007. Morb Mortal Wkly Rep 58:337-341

Kurdi SEI, Mohammed AK, Eley A (2007) Enteric pathogens: experience of a tertiary hospital in the United Arab Emirates in 2006. Emirates Med J 25:301-305

Liu L, Oza S, Hogan D, Chu Y, Perin J, Zhu J, Lawn JE, Cousens S, Mathers C, Black RE (2016) Global, regional, and national causes of under-5 mortality in 2000-15: an updated systematic analysis with implications for the sustainable development goals. Lancet 388:3027-3035

Memish ZA, Jaber S, Mokdad AH, AlMazroa MA, Murray CJL, Al Rabeeah AA (2014) Burden of Disease, Injuries, and Risk Factors in the Kingdom of Saudi Arabia, 1990-2010. Prev Chronic Dis 11

Mokdad AH, Jaber S, Aziz MIA, AlBuhairan F, AlGhaithi A, AlHamad NM, Al-Hooti SN, AlJasari A, AlMazroa MA, AlQasmi AM (2014) The state of health in the Arab world, 1990-2010: an analysis of the burden of diseases, injuries, and risk factors. Lancet 383:309-320

Organization WH (2000) The world health report 2000: health systems: improving performance. World Health Organization, Geneva

Patel, P.K., Mercy, J., Shenoy, J. and Ashwini, B., 2008. Factors associated with acute diarrhoea in children in Dhahira, Oman: a hospital-based study. EMHJ-Eastern Mediterranean Health Journal, 14 (3), 571-578, 2008.

Shafik CF, Mohareb EW, Yassin AS, Amin MA, El Kholy A, El-Karaksy H, Youssef FG (2012) Viral etiologies of lower respiratory tract infections among Egyptian children under five years of age. BMC Infect Dis 12:350

Sweileh WM, Al-Jabi SW, Abuzanat A, Sawalha AF, AbuTaha AS, Ghanim MA, Zyoud SH (2015) Assessment of research productivity of Arab countries in the field of infectious diseases using Web of Science database. Infect Dis Poverty 4(1)

Tate JE, Burton AH, Boschi-Pinto C, Parashar UD, Network WHO-CGRS, Agocs M, Serhan F, de Oliveira L, Mwenda JM, Mihigo R (2016) Global, regional, and national estimates of rotavirus mortality in children $<5$ years of age, 2000-2013. Clin Infect Dis 62:S96-S105

Wardlaw T, Salama P, Johansson EW, Mason E (2006) Pneumonia: the leading killer of children. Lancet 368:1048-1050

Youssef M, Shurman A, Bougnoux M-E, Rawashdeh M, Bretagne S, Strockbine N (2000) Bacterial, viral and parasitic enteric pathogens associated with acute diarrhea in hospitalized children from northern Jordan. Pathogens Disease 28:257-263 